\title{
From Scandinavia
}

\author{
Frank A Wollheim
}

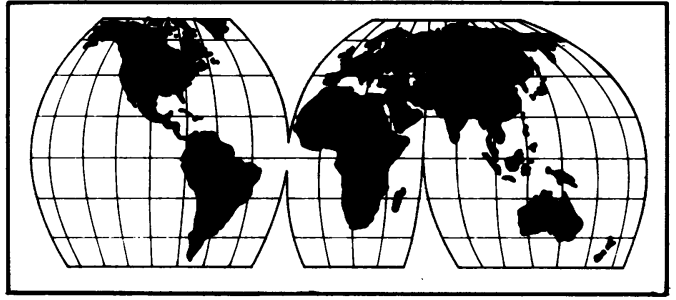

Norway

From Norway came the sad news of Eimar Munthe's (figure) untimely death from pancreatic carcinoma on 11 February 1990, at the age of 52. He was an untiring fighter for the advancement of the specialty in Norway, Scandinavia, Europe, and the world. The gap he left will be hard to fill. His successor as chief editor of the Scandinavian Fournal of Rheumatology is Gunnar Husby. The number of academic posts has been growing in Norway. Øystein Førre is now recipient of a research chair in Oslo and has together with Jacob Natvig launched interesting work on rheumatoid $T$ cell clones with known specificity, aiming at obtaining nucleotide sequences of the $T$ cell receptor. Furthermore, IgM rheumatoid factor genes will be cloned and the gene products studied in transgenic mice.

A chair of rheumatology is being created in Trondheim. Hans Martin Høyeraal now holds the first chair in Bergen. Accordingly, a European paediatric rheumatology workshop was arranged in Bergen in May 1990. Dr Høyeraal was also elected chairman of the Norwegian Rheumatologic Society in December 1989. In Tromsö the study of AA amyloid continues with cDNA technology by Professor Gudmund Marhaug. He and Gunnar Husby's group are delineating connections with the acute phase response. Another new approach is

Department of Rheumatology University Hospital of Lund, S-221 85 Lund, Sweden

F A Wollheim

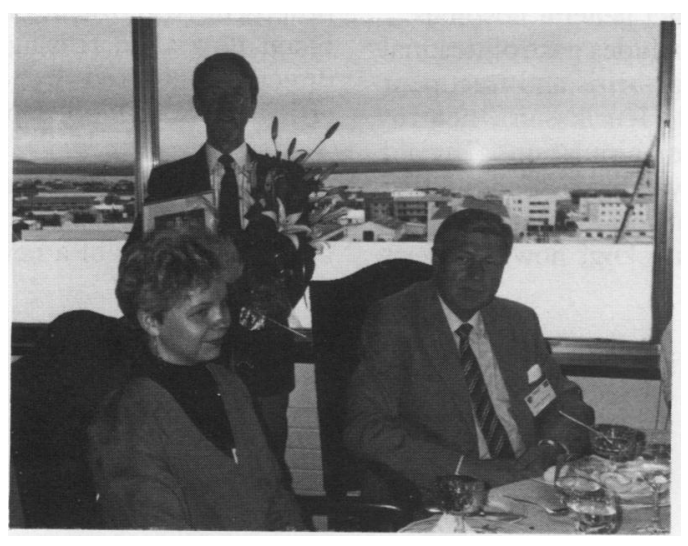

The late Eimar Munthe to the right at a prize ceremony in Reykjavik, Iceland, F une 1988. To the left the prize winner, Dr Tiinamaija Tuomi from Finland, and at the back Docent fon Thorsteinsson from Iceland, one of the founders of Icelandic rheumatology. the characterisation of a proteoglycan moiety of amyloid by Jeanette Magnus.

\section{Iceland}

In Iceland the unique epidemiology studies continue. After the work with systemic lupus erythematosus, patients with scleroderma are now being studied by Geirsson, who has found the disease rather mild in the 12 cases identified in Iceland. Also, the group with Professor Valdimarsson is studying prognostic implications of rheumatoid factors. The controversial claim that IgA rheumatoid factor carries a high risk for future erosive disease is an issue that needs clarification. Kristian Steinsen, who recently reported a new type of complement deficiency, is the chairman of the Icelandic Rheumatologic Society.

\section{Denmark}

In Denmark the first chair of rheumatology has been established at Aarhus. In Copenhagen both Gunnar Bendixen and Ib Lorenzen hold chairs of internal medicine, though the main thrust of their departments is rheumatological teaching and research. In Copenhagen the interleukins are being studied by Klaus Bendtzen. Jörgen Pedersen is collaborating with Dennis Carson to investigate a possible aetiological role for the Epstein-Barr virus in rheumatoid arthritis. In November 1989 Troels Mørk-Hansen at Herlev University Hospital organised the second Scandinavian allied health profession meeting in Copenhagen, which was well attended and successful. These meetings will take place every second year, and in 1991 Finland will be the host country.

\section{Finland}

In Finland much effort has been devoted to preparing the 23rd Scandinavian congress of rheumatology in 1990. Professor Heikki Isomäki was its president, and the venue was a new congress centre in Tampere.

Dr Heikki Vanharanta was appointed to Finland's first professorship in physiatry, at the University of Oulu. In Finland conservative treatment of musculoskeletal disease has been shared between rheumatologists and physiatrists. Rheumatologists have been responsible for the treatment of inflammatory diseases, while physiatrists have treated non-inflammatory diseases, such as low back pain.

Professor Kauko Vainio, former head of the orthopaedic department of the Rheumatism Foundation Hospital, Heinola, died on 17 January 1989. He joined the hospital staff in 1952 and embarked on investigative operations on rheumatoid patients. His results attracted enthusiastic 
international attention in the $1960 \mathrm{~s}$, and he was known among specialists as 'the father of rheumatoid surgery'. He was a skilled ornithologist and an expert botanist. These remained his hobbies after retirement in 1975.

According to a recent study made by the Social Insurance Institution, patients visit the doctor most commonly because of acute respiratory infection. Only 10 years ago cardiovascular diseases were the second most common reason but in the last study, carried out in 1987, musculoskeletal diseases had risen to second place. Eight per cent of patients visiting a primary care doctor because of a musculoskeletal problem needed to consult a specialist (orthopaedic surgeon, rheumatologist, physiatrist).

Reactive arthritis continues to be prominent in Finland, although perhaps owing to improved hygiene in the slaughterhouses, yersinia arthritis is now less prevalent. Kaisa Granfors and Auli Toivanen in Turku were awarded the biennial prize by the Finnish Rheumatism Research Foundation for their work on the pathogenesis of reactive arthritis. Among recent advances is the detection of salmonella antigen in the joints of patients after salmonella arthritis. Decreased clearance of immune complexes was found in B27 negative patients with yersinia arthritis. Another mechanism is advocated by Marjatta Leirisalo and Heikki Repo in Helsinki, who produced further evidence of increased polymorphonuclear reactivity as a contributing factor in B27 positive patients with reactive arthritis.

The inflammatory reaction is studied by Peter Maury in Helsinki, who showed that interleukin-1 is a humoral inhibitor of erythropoiesis. In Tampere Heikki Vapaatalo in collaboration with Heikki Isomäki studied eicosanoid metabolism and found synovial leucotriene $B_{4}$ to originate mainly in polymorphonuclear leucocytes, whereas prostaglandin $E_{2}$ is produced in synovial lining cells. Furthermore, Moitanen in this group produced evidence that some non-steroidal antiinflammatory drugs depressed leucotriene $B_{4}$ production in vivo.

\section{Sweden}

In Sweden a new specialist education system is being planned, which will increase the training period from four and a half to six years and which will include a voluntary examination. Rheumatology remains an independent specialty with established units at all district general hospitals.

Research in Stockholm includes gastrointestinal dysfunction in rheumatoid arthritis and treatment with misoprostol (Kenneth Henriksson), neutrophil function and diet manipulation (Ingiäld Hafström). At Huddinge Eva Hedfors is initiating a prospective analysis of syndromes related to antiRNP. In Uppsala Lars Klareskog, now professor of medical immunology, and collaborators showed expression of $65 \mathrm{kD}$ heat shock protein in the cartilage-pannus region and in subcutaneous nodes in rheumatoid arthritis, thus providing evidence for a possible pathogenic role for $\mathrm{T}$ cells reactive with this protein. Work is also in progress on an enzyme linked immunosorbent assay (ELISA) for fragments derived from human collagen II. His pupil, Rikard Holmdahl, now leading a very active group of his own, is concentrating on the collagen II model of arthritis and its control. At the section of rheumatology, headed by Roger Hällgren, systemic sclerosis is studied with particular attention to the cardiac vasospasm induced by cold and long term effects of angiotensin converting enzyme inhibitors. A new jejunal perfusion technique allowing analysis of local secretion of immunoglobulins and inflammatory mediators is being used to gain insight into gut pathophysiology in arthritis. The role of eosinophilic activation in arthritis is also studied as well as tissue accumulation of hyaluronate and its putative role in interstitial oedema. In Gothenburg Andrej Tarkowski and Hans Carlsten are studying NZB and MRL mouse disease and its relation to sex hormones. In Malmö Bjarne Hansen found that lachrymal and salivary dysfunction in a population study correlated with the presence of antibodies to SS-B. Rolf Manthorpe and his group maintain that primary Sjögren's syndrome is extremely common, occurring four times more often than rheumatoid arthritis in people aged 52 to 72 . In Lund the prospective study of a group with systemic lupus erythematosus continued and six year results were presented in a thesis by Helgi Jonsson. Systemic lupus erythematosus is a rather mild disease in Lund and major flares were concentrated to the first years of illness. In contrast, Kerstin Eberhardt found erosions in $60 \%$ of patients with rheumatoid arthritis followed up for two years after a median duration of 11 months at the start. Progressing erosions contrasted with improvement in clinical and laboratory measures. This group of patients is now being studied prospectively with, among other items, markers of cartilage metabolism in an attempt to identify prognostic markers. The marker work by Tore Saxne, Dick Heinegård, and others is producing exciting results, which were reviewed at the November 1989 meeting of the British Society for Rheumatology. Pierre Geborek presented a thesis on joint pathophysiology in which a new expression for capsular stiffness allowing comparative and prospective studies was proposed. Also, the negative influence on synovial blood flow at increasing joint fluid volumes was directly registered by application of an intraarticular laser Doppler probe.

Thus despite a shrinking public health economy, Scandinavian rheumatology is vital and optimistic at the beginning of a new decade. 